\title{
O meu, o teu, o nosso dinheiro: Contributos para o estudo da gestão das finanças conjugais em Portugal
}

My Money, Your Money, Our Money: Contributions to the Analysis of Couples'

Financial Management in Portugal

Mon, ton, notre argent: contributions à l'étude de la gestion des finances

conjugales au Portugal

\section{Lina Coelho}

\section{(2) OpenEdition}

\section{Journals}

Edição electrónica

URL: http://journals.openedition.org/rccs/5378

DOI: $10.4000 /$ rccs.5378

ISSN: 2182-7435

\section{Editora}

Centro de Estudos Sociais da Universidade de Coimbra

\section{Edição impressa}

Data de publição: 1 setembro 2013

Paginação: 89-110

ISSN: 0254-1106

\section{Refêrencia eletrónica}

Lina Coelho, «O meu, o teu, o nosso dinheiro: Contributos para o estudo da gestão das finanças

conjugais em Portugal», Revista Crítica de Ciências Sociais [Online], 101 | 2013, posto online no dia 17 fevereiro 2014, consultado o 04 fevereiro 2021. URL: http://journals.openedition.org/rccs/5378 ; DOI: https://doi.org/10.4000/rccs.5378 


\section{LINA COELHO*}

\section{O meu, o teu, o nosso dinheiro: Contributos para o estudo da gestão das finanças conjugais em Portugal}

A relação entre conjugalidade e gestão das finanças familiares e, em particular, o modo como as normas sociais dominantes sobre género e casamento influenciam os comportamentos financeiros, as relações de poder e os comportamentos de consumo e partilha de recursos pelos cônjuges, está ainda por estudar em Portugal. Estudos realizados em outros países mostram que diferentes sistemas de gestão das finanças familiares se relacionam, de forma complexa, com o acesso a recursos, o bem-estar e a satisfação dos diferentes membros da família. O presente artigo constitui um contributo para a compreensão desta problemática no contexto português, ao discutir a complexidade das negociações e decisões financeiras intrafamiliares, ao mesmo tempo que ensaia uma aplicação à realidade portuguesa da tipologia sobre modos de gestão e controlo das finanças familiares desenvolvida por Jan Pahl e Carolyn Vogler, com recurso a dados do Inquérito às Condições de Vida e Rendimento de 2010 do INE.

Palavras-chave: comportamento do consumidor; finanças pessoais; gestão financeira; questões de género; tomada de decisão.

\section{Introdução}

A maioria das pessoas vive grande parte da sua vida em famílias plurais, tipicamente ancoradas num casal, e partilhando recursos familiares comuns, que é preciso gerir. As decisões económicas e financeiras familiares são pois necessariamente determinadas, em alguma medida, por lógicas de cooperação e partilha, já que é preciso atender às necessidades de todos

\footnotetext{
* Este artigo foi escrito no âmbito do projeto "FINFAM - Finanças, Género e Poder: como estão as famílias portuguesas a gerir as suas finanças no contexto da crise?" (PTDC/IVC-SOC/4823/2012 - FCOMP-01-0124-FEDER-029372), financiado por Fundos FEDER através do Programa Operacional Fatores de Competitividade - COMPETE e por Fundos Nacionais através da Fundação para a Ciência e a Tecnologia (FCT).
} 
os membros da família. Quando um novo casal se constitui, estas decisões, antes individuais, passam a ter que ser partilhadas, situação que resulta reforçada com o surgimento de filhos.

Uma vez que as preferências individuais são, por vezes, divergentes ou até mesmo conflituais, as decisões familiares resultam de interações complexas, envolvendo negociação entre os cônjuges, tácita ou explícita. Esta versa, desde logo, a própria definição da esfera de responsabilidade de cada pessoa na gestão do rendimento conjunto, daí decorrendo consequências sobre as decisões de despesa e poupança ou endividamento e a necessidade (ou não) de também as negociar.

Embora estejam bem documentadas muitas das mudanças profundas das famílias portuguesas nas últimas décadas (em termos sociodemográficos, económicos, nas relações interpessoais e no relacionamento com outras instituições), continuam por estudar as perceções, negociações e práticas financeiras dos casais. $\mathrm{O}$ presente artigo pretende contribuir para superar esta lacuna. Assim, começa por apresentar um enquadramento teórico acerca dos modos como as normas e representações sociais sobre casamento e género influenciam os comportamentos financeiros das famílias, as decisões de consumo e poupança, a partilha intrafamiliar de recursos, as relações de poder e o bem-estar dos membros da família. Num segundo momento, faz-se uma breve análise da realidade portuguesa, com base em dados do Inquérito às Condições de Vida e Rendimento (ICOR) de 2010 do INE. Este exercício, ainda que limitado na sua abrangência e profundidade analíticas, permite ensaiar a aplicação a Portugal da tipologia sobre modos de gestão e controlo das finanças familiares desenvolvida por Jan Pahl e Carolyn Vogler, tipologia esta que constitui a ferramenta metodológica mais comummente usada nos estudos empíricos sobre esta temática.

\section{Economia da família e finanças familiares: dinheiro, género e poder}

A importância da pesquisa sobre práticas financeiras dos casais tem sido afirmada na literatura (Dew, 2008). Conhecer os padrões de despesa, o controlo sobre os recursos e os processos de tomada de decisão dos casais em matéria financeira releva, não só para a compreensão dos comportamentos económicos da família mas, também, para informar intervenções de diversa natureza para promoção do bem-estar familiar.

Trata-se de uma problemática complexa, determinada por uma multiplicidade de caraterísticas das famílias e dos contextos em que elas operam, ao mesmo tempo que tem, ela própria, implicações em domínios diversos da vida familiar. Tal justifica que constitua objeto de estudo para várias disciplinas científicas (Dew, 2008; Waseem, 2004). 
A teoria económica tradicional trata a família como uma unidade, cujos membros agem em perfeita sintonia de propósito para maximizar a satisfação das suas necessidades. Supõe-se assim não haver divergências de interesses ou preferências no seio da família, seja porque ocorre consenso, seja porque o chefe de família, principal provedor de sustento, detém a capacidade para fazer valer as suas próprias preferências através das transferências de rendimento que faz para os restantes familiares (Becker, 1981, 1991). Neste quadro, a alocação dos recursos familiares é invariante com a origem e a titularidade dos rendimentos. A família é um "agente económico representativo" que, no quadro da restrição de rendimento a que está sujeita, adota um comportamento económico eficiente.

Trata-se de uma leitura da família que não corresponde à experiência vivida por muitas pessoas, desde logo porque " $[\ldots]$ a prevalência de fenómenos destrutivos e perdulários como a violência doméstica e o abuso de crianças, ou a procura por aconselhamento matrimonial e terapia familiar, aconselham que consideremos que o comportamento familiar nem sempre é eficiente" (Lundberg e Pollak, 1996: 150).

Não surpreende, pois, que tenham vindo a proliferar, na literatura económica mais recente, modelos baseados na teoria dos jogos, que caraterizam a interação conjugal como uma negociação entre dois indivíduos, com preferências individuais e poder de decisão diferenciados, onde a alocação intrafamiliar corresponde à solução do "jogo negocial” (Lundberg e Pollak, 1996). Estas abordagens são, no entanto, também elas limitadas pelo formalismo do método de análise que, ao conformar-se a um quadro rígido de hipóteses, resulta em seletividade do objeto analítico que impossibilita a generalização das conclusões obtidas a tipos diversos de família ou mesmo a diferentes estádios de evolução temporal de uma mesma família (Pollak, 1985: 600; Lundberg e Pollak, 2003). Daí que partilhemos a perspetiva de Sen $(1983,1985,1990)$ de que o estudo da família se deve fazer no quadro de uma teoria negocial qualitativa, centrada no conceito de "conflito cooperativo", que permita atender ao papel, quer da agência individual, quer das perceções relativas aos interesses, ao bem-estar, às contribuições e pretensões de cada membro da família.

Todas as negociações envolvem gestão de interesses individuais mas, no contexto da família, é de esperar que estes sejam em grande medida coincidentes, conduzindo a uma lógica de cooperação, determinada por altruísmo e boa vontade. Tal não significa a dissolução do interesse próprio, nem o desaparecimento de motivações e perceções individuais diversas, já que a individualidade de cada pessoa resulta de identidades múltiplas, associadas ao sexo, à classe social, à situação socioprofissional, à raça e à comunidade 
a que se pertence mas, também, à posição dentro da família. Todas influenciam o modo como cada pessoa percebe os seus interesses, bem-estar, obrigações, objetivos e legitimidade de comportamentos. A perceção acerca do interesse próprio e a perceção que os outros têm sobre a contribuição de cada um para o bem-estar da família são elementos determinantes da alocação intrafamiliar (Sen, 1983, 1985, 1990). Sen chama a atenção para o facto de, em algumas sociedades, as mulheres identificarem de tal modo o seu bem-estar individual com o da família que isso as impossibilita de equacionar de forma minimamente objetiva os seus próprios interesses (Sen, 1990: 126). Por outro lado, as atividades relacionadas com a sobrevivência e a reprodução da família tendem a ser encaradas como "não produtivas" o que condiciona a perceção social acerca da legitimidade das mulheres reivindicarem para si uma parcela justa dos rendimentos familiares (Sen, 1985: 197). O poder relativo de homens e mulheres na família depende da tecnologia social ${ }^{1}$ própria a cada comunidade que determina, inter alia, uma dada divisão sexual do trabalho e perceções estereotipadas sobre esforço e merecimento. O estudo dos comportamentos económicos das famílias deve pois reconhecer "[...] que ser-se homem ou mulher importa para determinar o modo como as decisões são tomadas e os recursos são alocados [...]" (Katz, 1997: 26). A formação e titularidade dos rendimentos familiares e o modo como estes são geridos constituem domínios privilegiados de expressão dos papéis sociais de género.

A este propósito, importa distinguir entre a gestão do dinheiro e o seu controlo (Edwards, 1982: 325). Este corresponde à tomada de decisão propriamente dita. Aquela corresponde à implementação das decisões, antes formuladas. É pois o controlo do dinheiro que expressa o poder de decisão sobre as finanças da família.

Esta leitura é concordante com muito do pensamento feminista das últimas décadas que aponta a dependência (total ou parcial) de rendimento das mulheres como condição para a manutenção da sua posição social subordinada (Lister, 1990; O'Connor, 1996; Ward et al., 1993), pois que "aqueles que têm poder sobre outros se reconhecem facilmente pelo facto de controlarem e terem acesso a recursos. E os recursos dão poder para controlar, recompensar e punir outros" (Jarl, 2003: 48).

Importa contudo assinalar que o acesso a rendimento próprio, e o putativo controlo daí decorrente, não se converte automaticamente em poder no seio da família pois, como já referido, as representações sociais sobre género

\footnotetext{
1 "Tecnologia social" é aqui entendida como "os arranjos sociais que tornam possíveis os processos produtivos", incluindo os aspetos relativos à divisão sexual do trabalho (Sen, 1985: 197).
} 
e casamento determinam os comportamentos dos homens e das mulheres, podendo resultar em práticas neutralizadoras ou atenuadoras da conversão dos recursos em efetivo poder de decisão. Daí que seja útil distinguir entre "poder estrutural" e "poder de natureza ideológica", sendo o primeiro um "poder de dominação - levar alguém a fazer o que queremos ou impedir uma pessoa de fazer outras coisas", e o segundo, "crenças, constructos e interpretações que moldam a maneira como pensamos sobre nós próprios e as nossas relações, por exemplo, os diferentes papéis, deveres e expetativas para os homens e as mulheres" (Dallos e Dallos, 1997: 10-11). Esta é uma distinção analiticamente fecunda por evidenciar que, mesmo na ausência de condicionamento às decisões baseado em violência ou limitação de acesso a recursos, os condicionamentos sociais e culturais das escolhas que cada pessoa faz determinam a capacidade de exercício de poder (também) no seio da família, daí resultando que,

[...] os diferenciais de poder económico podem ser reforçados ou reduzidos pelo poder ideológico. Em famílias com uma divisão tradicional do trabalho, em que as mulheres não estavam empregadas ou tinham um emprego a tempo parcial, a ideologia do homem provedor de sustento aumentava e reforçava o poder económico masculino. Por outro lado, em famílias em que as mulheres tinham um emprego a tempo integral e as origens de recursos económicos eram mais equilibradas, a ideologia do homem provedor de sustento ainda operava, limitando o poder das mulheres. (Pahl, 2007: par. 4.10)

Zelizer (1994, 2003) pôs em evidência o significado social do dinheiro, altamente diferenciado de acordo com a sua origem, os usos que lhe são dados e a pessoa que tem o direito de o usar. Diversamente do preconizado pelo discurso económico tradicional, o dinheiro não é fungível, porque existe incrustado nas relações sociais. Nessa medida, ele é também determinado pelos papéis sociais de género; as suas aplicações dependem de quem o obteve e de como foi obtido. Esta ideia encontra comprovação empírica em múltiplos estudos, com recurso a bases de dados sobre orçamentos e despesas familiares de sociedades com estruturas económicas e tradições culturais e religiosas muito diversas (Hoddinott e Haddad, 1995; Phipps e Burton, 1998; Thomas, 1990, 1993; Lundberg et al., 1997). ${ }^{2}$ Também Pahl (2000) analisou despesas das famílias britânicas no início da década de noventa, tendo concluído que as mulheres gastavam significativamente mais em alimentos, roupas e educação enquanto os

${ }^{2}$ Para maior detalhe sobre esta temática ver Coelho (2010: 58-63). 
homens despendiam mais em álcool, automóveis, reparações, refeições, jogos de azar e férias. Numa outra perspetiva, Bajtelsmit e Bernasek (1996) reviram literatura relativa a investimentos financeiros, tendo encontrado evidência de que as mulheres alocam as suas carteiras de forma diferente dos homens, preferindo opções de menor risco. Ou seja, num casal, quem ganha o dinheiro, e de que maneira, determina as suas aplicações e quem delas beneficia (nomeadamente porque as mulheres privilegiam as despesas em favor das crianças).

As desigualdades de género na família só parcialmente têm sido colmatadas pela contribuição crescente das mulheres para os orçamentos familiares, resultante da sua participação no mercado de trabalho. Na verdade, as mulheres auferem de menores remunerações médias, dada a prevalência de um hiato salarial de género, e tendem a ser penalizadas pela maternidade, que conduz ao atenuar da sua dedicação à carreira, em conformidade com os papéis de género prevalecentes, num momento em que as despesas aumentam significativamente (Waldfogel, 1998). A eventual manutenção de uma distribuição equitativa de recursos no casal exige pois uma redefinição dos modos de gestão das finanças comuns aquando do surgimento dos filhos. Se tal não ocorrer, a maternidade pode ser muito penalizante em termos económicos (Pahl, 2000; Vogler, 1998).

No que diz respeito a Portugal, dispomos hoje de uma abundante literatura sociológica sobre os modos como as representações sociais de género se manifestam na família e determinam a organização da vida familiar (Aboim, 2010; Perista, 2002; Portugal, 2006, 2013; Torres, 2001, 2008; Torres, Guerreiro e Lobo, 2007; Torres et al., 2001; Torres et al., 2004; Wall, 2007; Wall e Amâncio, 2007; Wall e Guerreiro, 2005). No seu conjunto, estes estudos revelam um quadro de evoluções significativas, não lineares e complexamente articuladas, nas relações sociais de género. Assim, se por um lado o aumento sustentado da participação feminina no mercado de trabalho nas últimas décadas constituiu um forte vetor de transformação social com impacto pronunciado nas relações de género e na vida familiar, por outro, permanecem "valores maternalistas, largamente partilhados por homens e por mulheres, [que] constituem peça fundamental no esquema da desigualdade" (Aboim, 2010: 63). Embora o modelo de duplo emprego a tempo inteiro se tenha tornado claramente prevalecente nas famílias portuguesas, e haja evidência de crescente participação masculina nas tarefas domésticas, os papéis tradicionais de género mantêm-se atuantes, fazendo recair sobre as mulheres uma parcela desproporcional do trabalho doméstico e de cuidado às pessoas. Daí resultam manifestas desigualdades de tempo de trabalho efetivo entre 
homens e mulheres, com estas a enfrentarem dificuldades acrescidas na conciliação entre vida profissional, familiar e pessoal.

Neste quadro é de prever que as desigualdades de género se manifestem também no domínio da gestão financeira das famílias.

\section{Modos de gestão e controlo das finanças familiares: uma tipologia}

Os trabalhos de Jan Pahl e Carolyn Vogler revestem especial interesse para a compreensão da forma como os casais gerem os seus orçamentos familiares (Pahl, 1980, 1989, 1995, 2008; Vogler, 2005; Vogler et al., 2006; Vogler e Pahl, 1993, 1994). As autoras estudaram casais britânicos (heterossexuais, casados ou em união marital e com filhos dependentes), recorrendo a inquéritos e entrevistas de amplitudes e incidências diversas, ao longo de cerca de três décadas. Os resultados obtidos permitiram elaborar tipologias de gestão e controlo dos orçamentos familiares, a partir da proposta de Pahl (1980, 1983), que identifica quatro principais modos de gestão do dinheiro: gestão por um dos cônjuges, mesada para governo da casa, gestão conjunta e gestão independente. Esta proposta foi sendo adaptada e resultou, numa versão mais recente, em seis modalidades, das quais duas correspondem a desdobramentos das anteriores (cf. Quadro 1; Pahl, 1983, 1995; Vogler, 1998; Vogler et al., 2006; Vogler, Brockmann e Wiggins, 2008; Vogler e Pahl, 1993, 1994).

A tipologia baseia-se no acesso de cada cônjuge ao dinheiro e na sua esfera de responsabilidade relativamente às despesas da família, permitindo evidenciar um padrão complexo de inter-relações entre modalidades de gestão, valores e titularidades do rendimento e ideologia de género.

A modalidade mesada para governo da casa é caraterística de casais em que só o homem aufere um salário e entrega à mulher um montante de valor fixo para assegurar as despesas correntes. $\mathrm{O}$ rendimento restante é gerido por ele, que também define o valor da própria mesada. Esta modalidade tem vindo a perder expressão ao longo do tempo.

$\mathrm{Na}$ modalidade gestão integral o marido (predominantemente) entrega a quase totalidade do seu salário à mulher para que esta assegure a respetiva gestão, podendo ele reservar uma parcela menor do dinheiro para as suas despesas pessoais. A mulher é assim inteiramente responsável pelas despesas da família. Ocorre predominantemente em famílias com rendimentos reduzidos, nas quais a gestão do orçamento é uma tarefa árdua, porque se trata de "fazer render" recursos insuficientes para satisfazer as necessidades da família. A gestão integral pelo marido, por seu lado, carateriza sobretudo casais com rendimentos elevados, em que ele é o principal titular de rendimento. Pode também andar associada a práticas de violência doméstica, em que a mulher é sujeita a situações de privação material. 


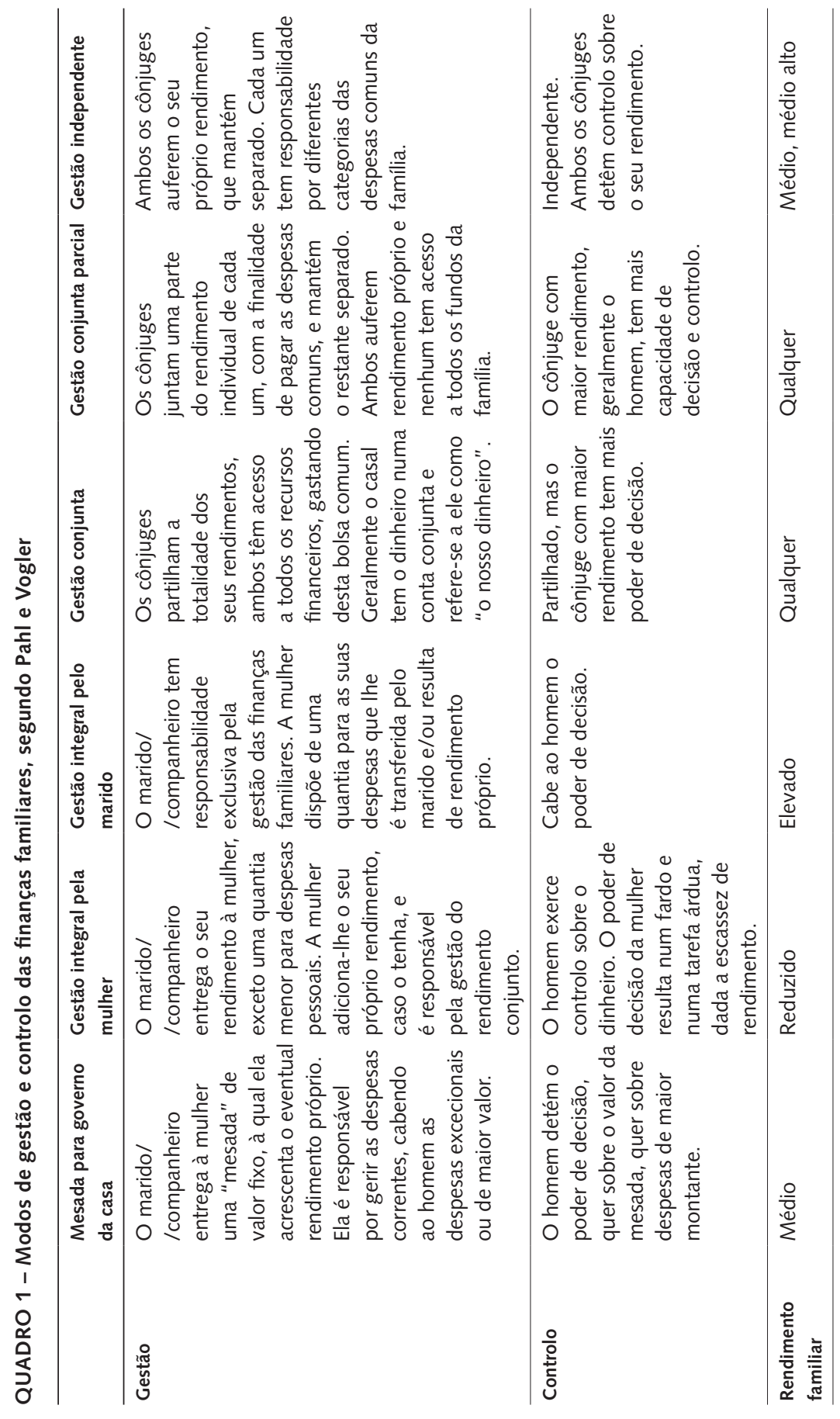




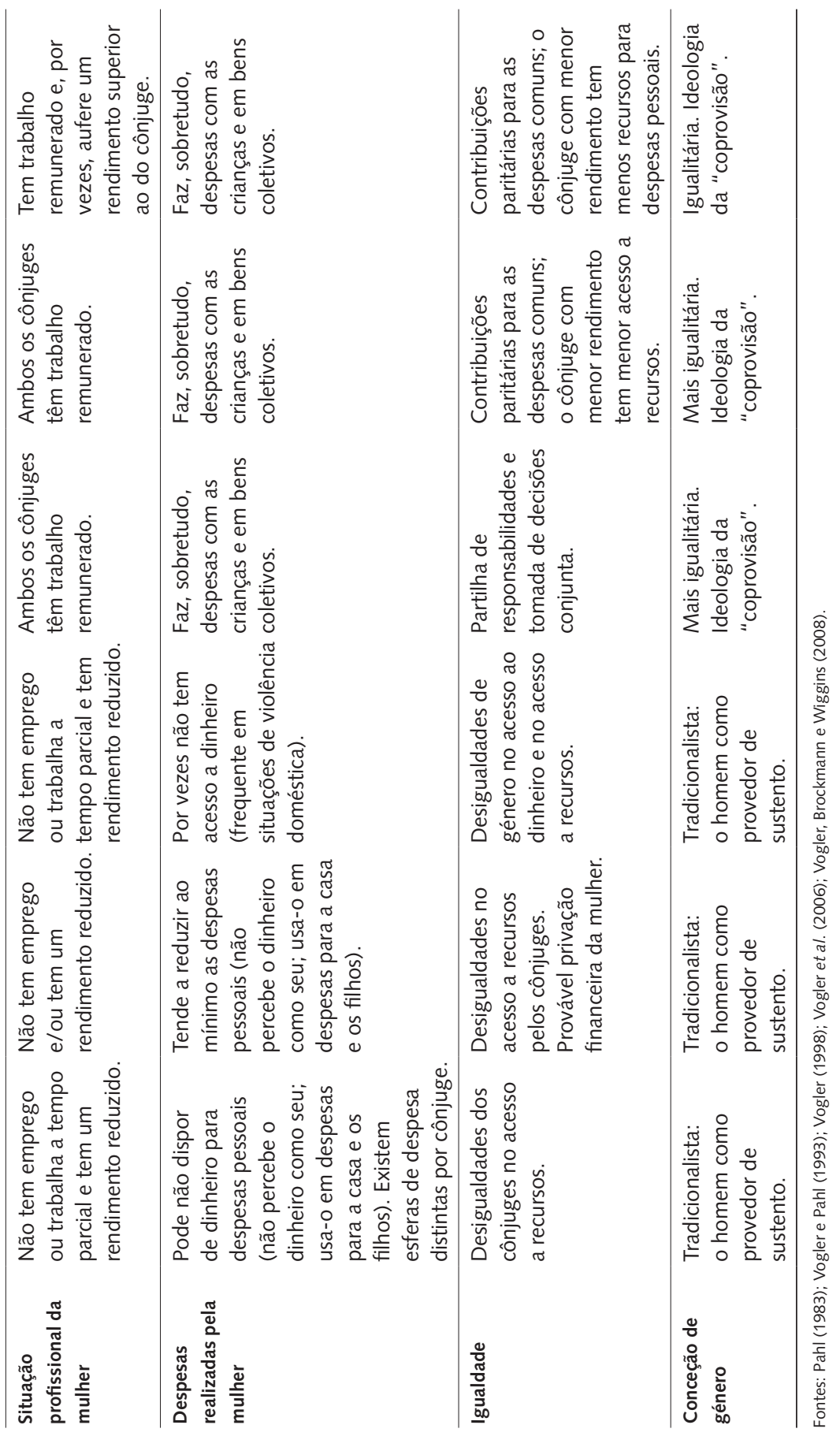


No sistema de gestão independente ambos os cônjuges auferem rendimento próprio, sendo responsáveis por diferentes categorias das despesas comuns. Ocorre predominantemente em famílias com rendimentos médios e médios altos, casais jovens ou famílias recompostas. Assume expressão reduzida, ainda que crescente.

$\mathrm{Na}$ modalidade gestão conjunta, os cônjuges têm idêntico acesso ao dinheiro, que juntam, e as despesas são responsabilidade de ambos. Carateriza casais em que a mulher também aufere salário. Pode assumir a forma de gestão conjunta parcial, se só a parte do rendimento destinada às despesas comuns for reunida e gerida conjuntamente. Este é o sistema mais usual e tem vindo a ganhar peso ao longo do tempo. É o mais conforme à ideologia de comunhão que prevalece sobre o casamento. A comunhão de rendimento não impede, no entanto, que um dos cônjuges tenha maior controlo sobre as finanças familiares. Por exemplo, Vogler e Pahl (1993) constataram que, de entre os casais que juntavam os rendimentos, só 39\% afirmavam serem ambos igualmente responsáveis pelas decisões.

O controlo sobre o dinheiro afere-se pela capacidade de cada cônjuge decidir sobre os usos do dinheiro, efetuar autonomamente despesas dirigidas à satisfação de necessidades pessoais e/ou efetuar despesas de caráter excecional ou de montante elevado. São assim identificáveis quatro sistemas de controlo - pela mulher, pelo marido, partilhado e independente.

O nível de rendimento e a sua titularidade relevam para a forma como o dinheiro é gerido e controlado. A pessoa que ganha a maior parte do dinheiro é a que tem maior probabilidade de o controlar. No entanto, a ideologia sobre género e casamento interferem na opção adotada, entre outras determinantes.

Em síntese, a escolha do sistema de alocação é influenciada pelo rendimento (famílias com baixos rendimentos tendem a usar sistemas geridos pelas mulheres), pela ideologia ou representações de género (uma ideologia tradicional, que vê o homem como provedor de sustento da família, aumenta a probabilidade de controlo pelo homem), pela relação com o mercado de trabalho (famílias em que só o homem tem emprego ou em que a mulher tem emprego a tempo parcial ou com baixa remuneração tendem a usar sistemas geridos pela mulher), pela escolaridade dos cônjuges (maior escolaridade aumenta a probabilidade de partilha de recursos e divisão de responsabilidades), pela socialização parental (o sistema usado pelos pais influencia as opções) e pelo tipo de família ou de relação conjugal (casais em união marital, casais sem filhos e famílias recompostas tendem à segregação de rendimentos e de esferas de despesa) (Anu, 2011; Burgoyne et al., 2007; Pahl, 1995, 2008; Singh e Morley, 2010; 
Vogler, 1998; Vogler et al., 2006; Vogler, Lyonette e Wiggins, 2008; Vogler e Pahl, 1993, 1994).

A desigualdade de género tende a ser menos pronunciada para casais com controlo conjunto do dinheiro posto em comum, e particularmente pronunciada nas famílias com controlo masculino das finanças (Pahl, 1995; Vogler, 1998; Vogler et al., 2006).

Estudos realizados em outros países (Estados Unidos, Austrália, Alemanha, Suécia, Espanha) confirmaram, no essencial, os resultados apresentados (Ludwig et al., 2011; Pahl, 2008). Tal não significa, no entanto, que estes sejam generalizáveis a outras partes do mundo (Pahl, 2008).

\section{Gestão financeira dos casais em Portugal: uma abordagem exploratória}

Num estudo realizado em 1995 pelo Instituto de Ciências Sociais da Universidade de Lisboa, a influência dos papéis de género na gestão financeira dos casais surge evidenciada no facto de os homens assumirem maioritariamente a responsabilidade pela gestão das contas bancárias, empréstimos e impostos, enquanto as mulheres relatavam decidir sobre os gastos domésticos habituais nas compras de menor valor (CIDM, 2001: 59). Mais recentemente, Gomes (2000) desenvolveu uma investigação exploratória sobre o tema, aplicando entrevistas semiestruturadas a casais heterossexuais, tendo concluído também que as representações sobre casamento e género relevam no domínio da gestão financeira familiar. Os casais mais velhos revelaram praticar formas de gestão mais partilhadas e comungadas, como forma de expressão de comunidade conjugal, situação menos comum em casais mais jovens ou famílias recompostas (Gomes, 2000: 166). Os comportamentos de consumo também manifestaram diferenciações de género, com as mulheres a assumirem mais as despesas domésticas e quotidianas (alimentação, limpeza doméstica, vestuário) e os homens as despesas com habitação (renda ou pagamento de empréstimos) e outras associadas (água, eletricidade, gás, telefone). A autora deteta a coexistência de dois princípios conflituantes na vivência conjugal - liberdade e autonomia individual, por um lado, coletivismo familiar, por outro - que, no entanto, nunca se anulam mutuamente, conduzindo a que a maioria dos casais partilhe, em alguma medida, recursos e decisões (ibidem: 169). Os arranjos de gestão financeira dos casais surgem plurideterminados por fatores como os níveis de rendimento individual, a fase da família no ciclo de vida, as caraterísticas psicológicas individuais, critérios de conveniência prática, representações sociais de género, geração de pertença e tipo de organização familiar.

Neste trabalho propomos um contributo adicional, ao procurar identificar e tipificar as modalidades de gestão e controlo das finanças familiares 
em Portugal, usando uma fonte secundária de informação. O Inquérito às Condições de Vida e Rendimento (ICOR) do INE é uma operação estatística, ${ }^{3}$ realizada por entrevista direta junto de uma amostra representativa de agregados familiares, que contém um módulo anual especializado cuja temática, em 2010, foi precisamente a partilha de recursos no seio do agregado doméstico privado (ADP). ${ }^{4}$

O ICOR toma como unidade de observação e análise os ADP e os indivíduos que os constituem, sendo algumas variáveis inquiridas ao nível do ADP, através de entrevista à pessoa que se assume como representante da família, e outras ao nível do indivíduo, através de entrevista pessoal a cada membro do ADP com idade igual ou superior a 16 anos. Entre outra, é recolhida informação acerca da composição e das caraterísticas sociodemográficas das famílias e da composição, titularidade e natureza do rendimento familiar. O módulo específico de 2010 recolheu também informação sobre a gestão dos rendimentos comuns do agregado e o poder de decisão económica dos indivíduos que o compõem.

Para a presente análise foram selecionados os ADP compostos por pelo menos um casal heterossexual, casado ou em união marital, com ou sem filhos dependentes e vivendo ou não com outros adultos. Foram excluídos os agregados com rendimentos nulos e aqueles em que nenhum dos elementos do casal gere os recursos comuns.

Para aplicar a tipologia de Pahl e Vogler (Pahl, 1989, 2008; Vogler e Pahl, 1993), analisaram-se os dados relativos à titularidade dos rendimentos do casal; ao tratamento dado a esses rendimentos; à identidade da(s) pessoa(s) normalmente responsáveis pela gestão do orçamento comum; à proporção do rendimento individual mantida de forma separada do orçamento comum; e à identidade de quem toma decisões relativas a despesas correntes, despesas com bens de consumo duradouros e mobiliário dispendioso, empréstimos, poupanças, e despesas importantes em benefício das crianças. O Quadro 2 resume os critérios utilizados. Na sua aplicação foram encontrados dois tipos de "não conformidade". O primeiro corresponde a uma ou mais contradições entre as respostas dadas pelo representante do agregado e aquelas dadas pelos cônjuges nos questionários individuais. ${ }^{5}$

\footnotetext{
${ }^{3}$ Este inquérito é realizado anualmente em todos os países da União Europeia, com a designação genérica de European Union Statistics on Income and Living Conditions (EU-SILC).

${ }_{4}$ Agregado doméstico privado (ADP) é o "Conjunto de pessoas que residem no mesmo alojamento e cujas despesas fundamentais ou básicas (alimentação, alojamento) são suportadas conjuntamente, independentemente da existência ou não de laços de parentesco; ou a pessoa que ocupa integralmente um alojamento ou que, partilhando-o com outros, não satisfaz a condição anterior" (INE, 2010: 10).

5 É o caso, por exemplo, dos agregados cujo representante refere que todos os rendimentos são tratados como recursos comuns, mas em que pelo menos um dos cônjuges afirma manter mais de $50 \%$, ou mesmo a totalidade dos seus rendimentos, separados do orçamento comum.
} 


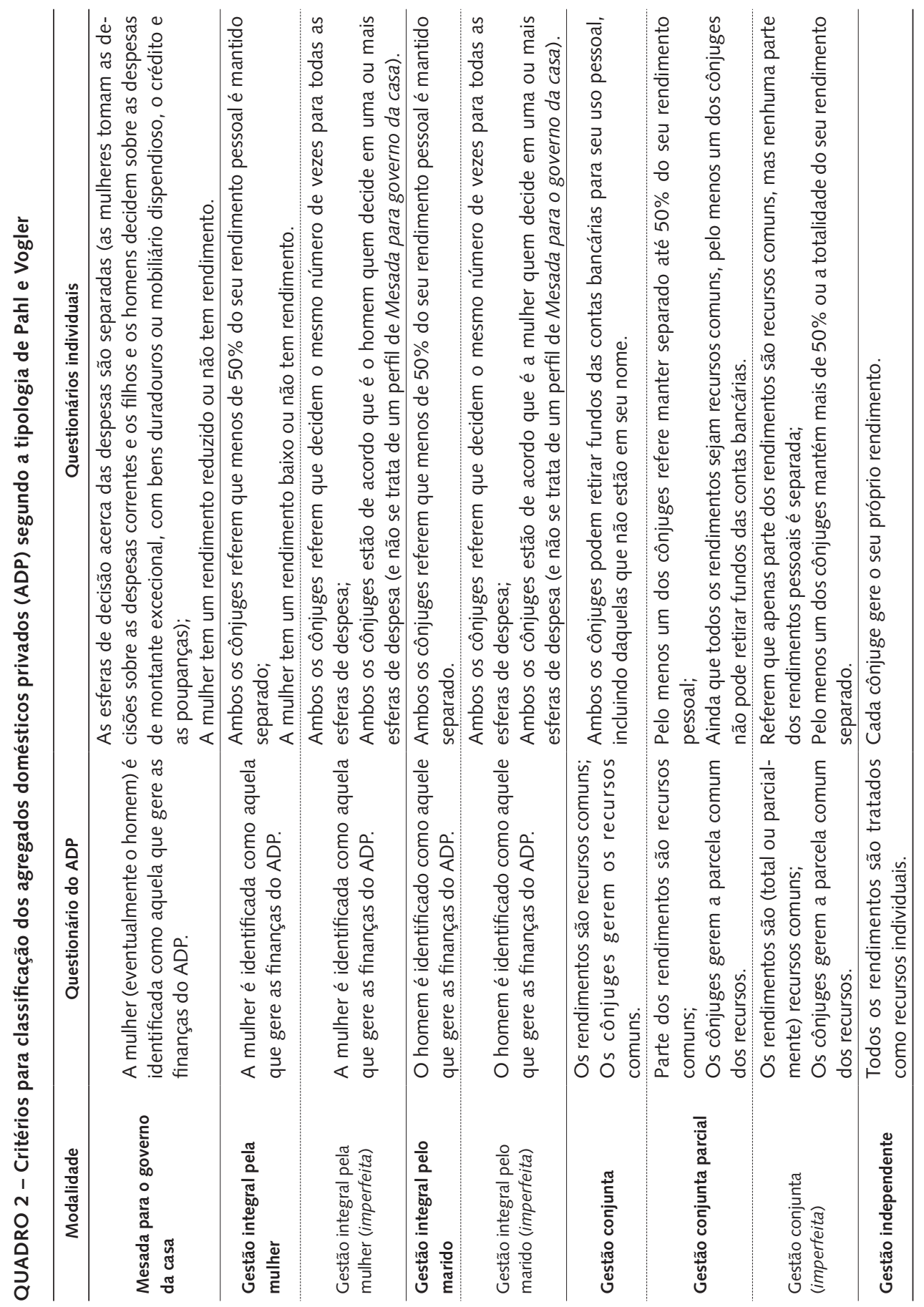


O segundo corresponde a situações em que o padrão de respostas é incongruente com pelo menos um dos critérios de classificação utilizados. ${ }^{6}$ Nos casos em que pelo menos uma destas situações se verificou, a forma de gestão do orçamento familiar aparece classificada como "imperfeita" (cf. Quadro 2).

A Tabela 1 sintetiza os resultados obtidos. A maioria dos casais portugueses declara juntar os seus rendimentos e tratá-los como recursos comuns (78,5\%), sendo muito menor o grupo dos que tomam apenas parte dos rendimentos como recursos comuns $(18,8 \%)$, e muito escassos os que tratam os rendimentos respetivos como recursos individuais totalmente separados $(2,7 \%)$.

Os valores obtidos apresentam um padrão de distribuição genericamente idêntico ao do conjunto dos países da UE, ainda que os valores concretos por país apresentem variabilidade significativa. Portugal surge com valores medianos no contexto geral (Eurostat, 2012). ${ }^{7}$ Esta regularidade confirma a prevalência de valores e práticas de comunhão de recursos no contexto do casamento, transversalmente às sociedades europeias, ainda que com modulações nacionais.

No que respeita às modalidades de gestão, a gestão conjunta, total ou parcial, é a mais utilizada (64,4\%). Mas a sua probabilidade diminui para as famílias recompostas, pois $11,7 \%$ destas mantêm os rendimentos totalmente separados, contra $2,7 \%$ das restantes famílias, e só $28 \%$ declaram partilhar e gerir conjuntamente todos ou parte dos rendimentos.

Os sistemas de gestão integral são utilizados por $29,5 \%$ dos agregados familiares, sendo a gestão integral pelo marido mais usual (18,7\%) do que a gestão integral pela mulher $(10,8 \%)$. As modalidades de mesada para governo da casa e gestão independente assumem incidências semelhantes, em torno de 3\%.

Estes resultados revelam-se pois genericamente concordantes com os apresentados na literatura relativa a outros países, com maior expressão dos sistemas de gestão partilhada e expressão residual para a modalidade de mesada e para a gestão independente.

Os valores médios de rendimentos e encargos das famílias, apresentados nas duas últimas colunas da Tabela 1 , parecem também confirmar algumas regularidades conhecidas. Assim, as modalidades de mesada e de gestão integral pela mulher parecem estar associadas a famílias com rendimentos e encargos mais reduzidos, em média, do que os restantes. Este é um aspeto a aprofundar em investigação futura.

\footnotetext{
${ }^{6}$ Deste segundo tipo de "não conformidade" são exemplo os agregados em que a mulher gere os recursos comuns do agregado, mas tem rendimento próprio superior ao do respetivo cônjuge.

${ }^{7}$ Estas conclusões referem-se à amostra total do inquérito, mais ampla do que a que selecionámos neste estudo. Não é, no entanto, de admitir que a ordenação relativa das grandezas se altere por esse facto.
} 
Contributos para o estudo da gestão das finanças conjugais em Portugal | 103

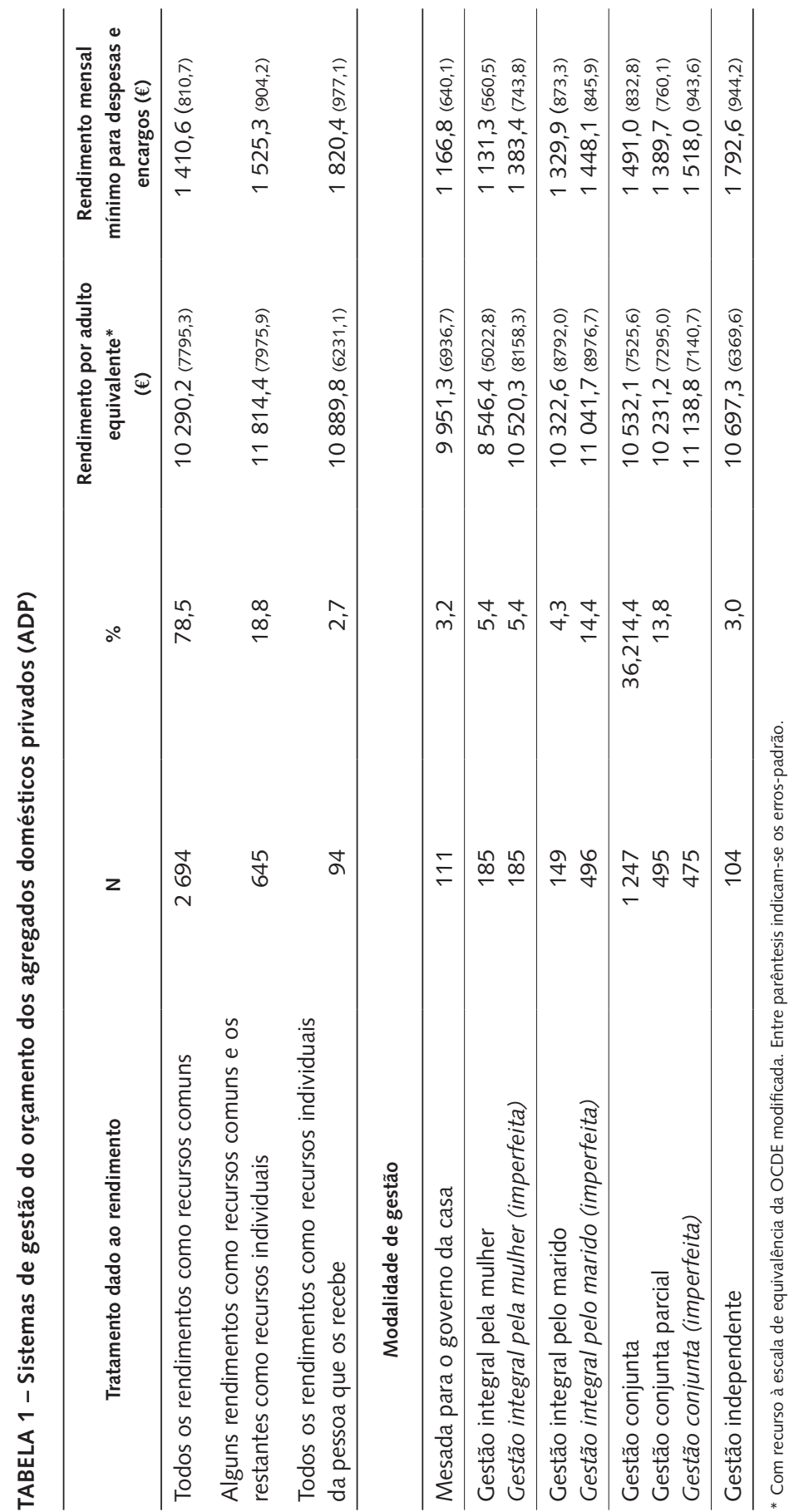


Foram detetadas inconsistências, entre as respostas do cônjuge que respondeu ao inquérito relativo à família e as respostas de cada cônjuge ao inquérito individual, em 33,6\% dos casais. Qualificámos estas situações como "imperfeitas" por não cumprirem cabalmente os critérios definidores da modalidade respetiva. ${ }^{8}$ As ocorrências respeitam às modalidades de gestão integral por um dos cônjuges $(19,8 \%$ ) e gestão conjunta, total ou parcial $(13,8 \%)$. Ainda que tal possa dever-se a erros de perceção ou registo, a sua expressão é suficiente para suscitar o aprofundamento futuro da análise, nomeadamente no sentido de perceber até que ponto as discrepâncias se devem a representações eventualmente dissonantes dos cônjuges acerca dos papéis de género e/ou do casamento ou a fatores de outra natureza como, por exemplo, o conhecimento incompleto de um dos cônjuges sobre a integralidade dos rendimentos e/ou da situação financeira da família.

\section{Conclusão}

O estudo dos modos de gestão das finanças familiares, com recurso a uma base de dados representativa da população, é um estudo pioneiro em Portugal. Embora a variedade de sistemas de gestão dos rendimentos conjugais seja enorme, o recurso a tipologias já provou ser uma ferramenta metodológica útil neste domínio, como demonstram os trabalhos de Jan Pahl e Carolyn Vogler. Os resultados preliminares de aplicação deste método à realidade portuguesa, aqui apresentados, sugerem padrões consonantes com a literatura disponível mas só o aprofundamento da pesquisa pode esclarecer eventuais especificidades da realidade portuguesa.

A elevada prevalência de casais com duplo emprego a tempo inteiro ou o facto de a família desempenhar um papel central como provedora de proteção social no caso português, diversamente do que acontece em outros países desenvolvidos (Santos, 1993; Hespanha, 1995; Portugal, 2006, 2013), constituem exemplos de especificidades suscetíveis de influenciar os modos de gestão financeira das famílias portuguesas.

Esta é uma problemática complexa, pelo que o aprofundamento do estudo requer abordagens interdisciplinares que, combinando perspetivas e métodos de análise complementares, permitam caraterizar as estratégias de negociação entre maridos e mulheres, estabelecer padrões sistemáticos de

\footnotetext{
${ }^{8}$ Este tipo de dificuldades na operacionalização da tipologia foi já assinalado por outros autores que apontaram como justificações possíveis o facto de as categorias utilizadas não serem mutuamente exclusivas e de alguns indivíduos interpretarem as questões de forma idiossincrática, assim como a dissemelhança entre os critérios de classificação usados e o padrão de respostas efetivamente dado por alguns casais (Ashby e Burgoyne, 2008; Bennett, 2013; Evertsson e Nyman, 2012).
} 
relação com diferentes estruturas, contextos e arranjos familiares ou detetar correlações com a estabilidade financeira da família, a equidade intrafamiliar no acesso a recursos e a satisfação com a vida conjugal e familiar.

Trata-se de uma agenda de investigação que assume especial relevância no contexto da crise económica atual, sendo de admitir que as famílias portuguesas estejam a rever e adaptar os seus modelos de gestão em consequência das restrições orçamentais acrescidas. É também de esperar que os ajustamentos em termos de despesa e padrões de vida afetem mais intensamente as mulheres (particularmente as mães de filhos dependentes) que, em consonância com os papéis de género tradicionais, poderão tender a acomodar mais a austeridade, sobretudo em famílias onde a desigualdade de género era maior à partida.

\section{Referências bibliográficas}

Aboim, Sofia (2010), "A vida familiar no masculino: negociando velhas e novas masculinidades”, in Karin Wall, Sofia Aboim e Vanessa Cunha (orgs.), Género, família e mudança em Portugal. Lisboa: Comissão para a Igualdade no Trabalho e no Emprego (CITE), 39-66.

Anu, Raijas (2011), "Money Management in Blended and Nuclear Families", Journal of Economic Psychology, 32, 556-563.

Ashby, Katherine; Burgoyne, Carole (2008), "Separate Financial Entities? Beyond Categories of Money Management”, Journal of SocioEconomics, 37, 458-480.

Bajtelsmit, Vickie; Bernasek, Alexandra (1996), "Why Do Women Invest Differently than Men?", Financial Counseling and Planning, 7, 1-10.

Becker, Gary (1981), A Treatise on the Family. Cambridge, Massachusetts: Harvard University Press.

Becker, Gary (1991), A Treatise on the Family (enlarged edition). Cambridge, Massachusetts: Harvard University Press.

Bennet, Fran (2013), "Researching Within-Household Distribution: Overview, Developments, Debates, and Methodological Challenges", Journal of Marriage and Family, 75, 582-597.

Burgoyne, Carole; Reibstein, Janet; Edmunds, Anne; Dolman, Valda (2007), "Money Management Systems in Early Marriage: Factors Influencing Change and Stability", Journal of Economic Psychology, 28, 214-228.

CIDM - Comissão para a Igualdade e para os Direitos das Mulheres (2001), Portugal, situação das mulheres, 2001. Lisboa: CIDM.

Coelho, Lina (2010), Mulheres, família e desigualdade em Portugal. Dissertação para Doutoramento em Economia. Coimbra: Universidade de Coimbra. Consultado a 21.06.2013, em https://estudogeral.sib.uc.pt/handle/10316/13833. 
Dallos, Sally; Dallos, Rudi (1997), Couples, Sex and Power: the Politics of Desire. Buckingham: Open University Press.

Dew, Jeffrey (2008), “Marriage and Finances”, in Jing Xiao (org.) Handbook of Consumer Finance Research. New York: Springer, 337-350.

Edwards, Meredith (1982), "Financial Arrangements Made by Husbands and Wives: Findings of a Survey", Journal of Sociology, 18, 320-338.

Eurostat (2012), "2010 EU-SILC Module on intra-household sharing of resources: Assessment of the implementation”. Consultado a 08.07.2013, em http://epp.eurostat.ec.europa.eu/portal/page/portal/income_social_inclusion_living_conditions/ documents/tab7/Assessment.pdf.

Evertsson, Lars; Nyman, Charlott (2012), "Perceptions and Practices in Independent Management: Blurring the Boundaries between 'Mine', 'Yours' and 'Ours'”, Journal of Family Economic Issues, 33, 389-506.

Gomes, Catarina (2000), "Quotidianos conjugais: a decisão financeira como forma de poder”, Forum Sociológico, 3-4(II Série), 157-178.

Hespanha, Pedro (1995), "A construção da habitação em meio rural: um domínio da sociedade-providência”, Revista Crítica de Ciências Sociais, 42, 125-153.

Hoddinott, John; Haddad, Lawrence (1995), "Does Female Income Share Influence Household Expenditures? Evidence from Côte d'Ivoire”, Oxford Bulletin of Economics and Statistics, 57(1), 77-96.

INE - Instituto Nacional de Estatística (2010), Módulo ICOR 2010 - Partilha de recursos no seio do agregado doméstico privado 2010: Documento metodológico. Consultado a 27.06.2013, em http://smi.ine.pt/UploadFile/Download/528.

Jarl, Ann-Cathrin (2003), In Justice: Women and Global Economics. Minneapolis: Fortress.

Katz, Elizabeth (1997), "The Intra-Household Economics of Voice and Exit”, Feminist Economics, 3(3), 25-46.

Lister, Ruth (1990), "Women, Economic Dependency and Citizenship", Journal of Social Policy, 19(4), 445-467.

Ludwig-Mayerhofer, Wolfgang; Allmendinger, Jutta; Hirseland, Andreas; Schneider, Werner (2011), “The Power of Money in Dual-earner Couples: A Comparative Study”, Acta Sociologica, 54(4), 367-383.

Lundberg, Shelly; Pollak, Robert (1996), "Bargaining and Distribution in Marriage”, Journal of Economic Perspectives, 10(4), 139-158.

Lundberg, Shelly; Pollak, Robert (2003), “Efficiency in Marriage”, Review of Economics of the Housebold, 1, 153-167.

Lundberg, Shelly; Pollak, Robert; Wales, Terence (1997), "Do Husbands and Wives Pool Their Resources? Evidence from the United Kingdom Child Benefit", The Journal of Human Resources, 32(3), 463-480.

O'Connor, Julia (1996), "From Women in the Welfare State to Gendering Welfare State Regimes”, Current Sociology, 44(2), 1-130. 
Pahl, Jan (1980), "Patterns of Money Management within Marriage”, Journal of Social Policy, 9, 313-335.

Pahl, Jan (1983), "The Allocation of Money and the Structuring of Inequality within Marriage", The Sociological Review, 31(2), 237-262.

Pahl, Jan (1989), Money and Marriage, London: Macmillan.

Pahl, Jan (1995), "His Money, her Money: Recent Research in Financial Organisation in Marriage", Journal of Economic Psychology, 16(3), 361-376.

Pahl, Jan (2000), “The Gendering of Spending within Households”, Radical Statistics, 75(Autumn), 38-48.

Pahl, Jan (2007), "Power, Ideology and Resources Within Families: a Theoretical Context for Empirical Research on Sleep”, Sociological Research Online, 12(5), 12. Consultado a 09.10.2009, em http://www.socresonline.org.uk/12/5/12.html.

Pahl, Jan (2008), "Family Finances, Individualisation, Spending Patterns and Access to Credit", Journal of Socio-Economics, 37, 577-591.

Perista, Heloísa (2002), "Género e trabalho não pago: os tempos das mulheres e os tempos dos homens”, Análise Social, XXXVII(163), 447-474.

Phipps, Shelley; Burton, Peter (1998), "What's Mine is Yours? The Influence of Male and Female Incomes on Patterns of Household Expenditure", Economica, 65, 599-613.

Pollak, Robert (1985), “A Transaction Cost Approach to Families and Households", Journal of Economic Literature, 33, 581-608.

Portugal, Sílvia (2006), "Women, Welfare State and Welfare Society in Portugal", in Maria Mesner; Gudrun Wolfgruber (orgs.), The Policies of Reproduction at the Turn of the 21st Century. Innsbruck: StudienVerlag, 41-54.

Portugal, Sílvia (2013), Família e redes sociais: Ligações fortes na produção de bem-estar. Coimbra: Almedina.

Santos, Boaventura de Sousa (1993), "O Estado, as relações salariais e o bem-estar social na semiperiferia: o caso português”, in Boaventura de Sousa Santos (org.), Portugal: um retrato singular. Porto: Edições Afrontamento, 17-56.

Sen, Amartya (1983), "Economics and the Family", Asian Development Review, 1(2), $15-26$.

Sen, Amartya (1985), "Women, Technology and Sexual Divisions", Trade and Development. An UNCTAD Review, 6, 195-223.

Sen, Amartya (1990), "Gender and Cooperative Conflicts”, in Irene Tinker (org.), Persistent Inequalities: Women and World Development. Oxford: Oxford University Press, 123-149.

Singh, Supriya; Morley, Clive (2010), "Gender and Financial Accounts in Marriage", Journal of Sociology, 47(1), 3-16.

Thomas, Duncan (1990), "Intrahousehold Resource Allocation: an Inferential Approach”, Journal of Human Resources, 25(4), 635-664. 
Thomas, Duncan (1993), “The Distribution of Income and Expenditure Within the Household”, Annales d'Économie et de Statistique, 29, 109-136.

Torres, Anália (2001), "Casamento e género: mudança nas famílias contemporâneas a partir do caso português", Revista Intersecções, 3, 53-70.

Torres, Anália (2008), "Women Gender and Work. The Portuguese in the Context of the European Union”, International Journal of Sociology, 38(4), 36-56.

Torres, Anália; Silva, Fernando V.; Monteiro, Teresa L.; Cabrita, Miguel; Jesus, F. (2001), "Trabalho e vida familiar: problemas, soluções e perplexidades", Cadernos de Política Social: Redes e Políticas de Solidariedade, 2-3, 29-48.

Torres, Anália; Cabrita, Miguel; Silva, Fernando V.; Monteiro, Teresa L. (2004), Homens e mulheres entre família e trabalho. Lisboa: Comissão para a Igualdade no Trabalho e no Emprego (CITE).

Torres, Anália; Guerreiro, Maria das Dores; Lobo, Cristina (2007), "Famílias em mudança. configurações, valores e processos de recomposição”, in Maria das Dores Guerreiro, Anália Torres e Luís Capucha (orgs.), Quotidiano e qualidade de vida. Oeiras: Celta Editora, 7-37.

Vogler, Carolyn (1998), "Money in the Household: Some Underlying Issues of Power", Sociological Review, 46(4), 687-713.

Vogler, Carolyn (2005), "Cohabiting Couples: Rethinking Money in the Household at the Beginning of the Twenty First Century", The Sociological Review, 53, 1-29.

Vogler, Carolyn; Brockmann, Michaela; Wiggins, Richard (2006), "Intimate Relationships and Changing Patterns of Money Management at the Beginning of the Twenty-First Ventury", The British Journal of Sociology, 57(3), 455-482.

Vogler, Carolyn; Brockmann, Michaela; Wiggins, Richard (2008), "Managing Money in New Heterosexual Forms of Intimate Relationships", Journal of Socio Economics, 37(2), 552-576.

Vogler, Carolyn; Lyonette, Clare; Wiggins, Richard (2008), "Money, Power and Spending Decisions in Intimate Relationships”, The Sociological Review, 56(1), 117-143.

Vogler, Carolyn; Pahl, Jan (1993), "Social and Economic Change and the Organization of Money in Marriage”, Work, Employment and Society, 7, 71-95.

Vogler, Carolyn; Pahl, Jan (1994), "Money, Power and Inequality within Marriage", The Sociological Review, 42(2), 263-289.

Waldfogel, Jane (1998), "The Family Gap for Young Women in the United States and Britain: Can Maternity Leave Make a Difference?”, Journal of Labor Economics, 16(3), 505-545.

Wall, Karin (2007), "Atitudes face à divisão familiar do trabalho em Portugal e na Europa”, in Karin Wall e Lígia Amâncio (orgs.), Família e género em Portugal e na Europa. Lisboa: Imprensa de Ciências Sociais, 211-257.

Wall, Karin; Amâncio, Lígia (2007), "Família e género, atitudes sociais dos Portugueses", in Karin Wall e Amâncio, Lígia (orgs.), Família e género em Portugal e na Europa. Lisboa: Imprensa de Ciências Sociais, 35-91. 
Wall, Karin; Guerreiro, Maria das Dores (2005), “A divisão familiar do trabalho”, in Karin Wall (org.), Famílias em Portugal-Percursos, interacções, redes sociais. Lisboa: Imprensa de Ciências Sociais, 303-362.

Ward, Clare; Heather, Joshi; Dale, Angela (1993), "Income Dependency within Couples", National Child Development Study Working Paper 36. London: Social Statistics Research Unit. Consultado a 08.07.2013, em http://www.cls.ioe.ac.uk/ library-media\%5Cdocuments\%5Cusgwp36.pdf.

Waseem, Saba (2004), "Household Monies and Decision-Making”, FaHCSIA Policy Research Paper, 23. Consultado a 20.06.2013, em http://www.fahcsia.gov.au/sites/ default/files/documents/05_2012/prp23.pdf.

Zelizer, Viviana (1994), The Social Meaning of Money. Harper Collins: New York.

Zelizer, Viviana (2003), "O significado social do dinheiro - Dinheiros especiais", in João Peixoto e Rafael Marques (orgs.), A Nova Sociologia Económica. Lisboa: Celta, 125-165. 
